\title{
College certification and recertification
}

F ew physicians have passed their final specialty examinations without thinking to themselves in relief, "Well, that's the last exam I'll ever have to take." It is a relief, but it may not be the last exam: the 2 Canadian colleges and many provincial licensing bodies are pondering more comprehensive relicensing and recertification standards, including examinations ${ }^{1}$ (see page 317 ).

The rapid pace of medical research means that physicians must devote more and more of their time simply to keeping up. Staying abreast of scientific progress has always been required, but physicians must also cope with an expanding scope of practice. For example, the Charter on Medical Professionalism ${ }^{2}$ includes as part of medical professionalism the continual practice of quality-of-care assessment and a commitment to work in teams to reduce medical error and improve patient outcomes. At the same time, patients are becoming increasingly well-informed and sophisticated users of health care services who no longer uncritically equate credentials with expertise and competence. Add to this a growing distrust of government and related authorities (and of the self-serving aspects of professional associations), and the result is pressure on the colleges to do a better job of assessing member competence.

The colleges have limted their efforts in this regard mainly to documenting participation in continuing medical education - a weak predictor of competence. There are no formal proctored examinations of knowledge and skills, such as those now required for continuing recertification in the United States. ${ }^{3}$

This slow progress is understandable. First, the expanding scope of professional practice adds complexity to the already difficult task of assessing physician competence. Assessments, to be valid and fair, must be comprehensive, and hence must encompass a range of criteria that are, in fact, difficult to measure. These include a commitment to lifelong learning, skill in the practice of multidisciplinary care, and ability to work successfully within and to assess systems of care, and competency in interpersonal communication, ethics and professionalism.

Second, there is a justifiable concern that current tools for assessing competence are unreliable and of only marginal validity. If this is true, it is not completely so - and these tools are getting better. Certainly, modern examination proce- dures, especially those used in recertification examinations of knowledge and case-management skills, have improved their psychometric characteristics and now correlate well with ongoing real-life assessments, at least among trainees.

Third, such comprehensive evaluations, done on a regular basis, are expensive. Although cost is a factor - as anyone who has taken part in recertification procedures in the US will attest - the costs are coming down. More and more of these assessments and examinations are carried out in a decentralized manner, using computer video enhancements, the Internet and other similar devices. Costs ought to continually decrease.

The colleges should move ahead rapidly to provide more rigorous systematic reevaluation and recertification procedures for their membership. Provincial licensing bodies are already ahead of them. In Alberta, for example, individual physicians are regularly evaluated by their patients, medical peers, consultants and referring physicians and coworkers. ${ }^{4}$ Similar efforts are under way in other provinces.

If the colleges do not assume aggressive leadership in physician evaluation, multiple (different and nontransferable) provincial relicensing examinations and procedures will emerge. We will also see other accrediting groups enter the field — such as the National Committee for Quality Assurance in the US, which has begun to accredit physicians for the management of specific diseases such as diabetes. ${ }^{5}$ A failure to move ahead will lead to increasing public distrust, lower the value of certification and, by allowing physicians to continue to practise without demonstrating that they meet current standards, will contribute to patient and public dissatisfaction, adverse events and poorer outcomes of care. - CMAF

\section{References}

1. Kondro W. Lifelong medical licences may end in 5 years. CMA7 2004; 171(4):317-8.

2. Medical professionalism in the new millennium: a physician charter. Ann Intern Med 2002;136(3):243-6. Available: www.annals.org/issues/v136n3/full /200202050-00012.html (accessed 2004 Jul 22).

3. Duffy FD, Zipes DP. The future of certification and recertification. Am 7 Med 2004;117:140-4.

4. Hall W, Violato C, Lewkonia R, Lockyer J, Fidler H, Toews J, et al. Assessment of physician performance in Alberta: the Physician Achievement Review. CMÄ 1999;161(1):52-7.

5. National Committee for Quality Assurance. Diabetes physician recognition program. Available: www.ncqa.org/dprp/ (accessed 2004Jul 23). 